\title{
The process of perceptual retouch: Nonspecific afferent activation dynamics in explaining visual masking
}

\author{
TALIS BACHMANN \\ Tartu State University, Tartu, Estonian SSR, U.S.S.R.
}

\begin{abstract}
A model for visual masking based on the notion of interaction of the specific and nonspecific afferent visual systems is presented. Discussion is focused on nonmonotonic masking functions. In particular, it is proposed that in order for visual information (patterns, forms, etc.) to be consciously perceived, both specific retino-geniculo-striate impulses and nonspecific retino-reticulocortical impulses should converge in the same cortical space. Nonspecific activity is shown to be necessary for subjective awareness. This activity is shown to be of longer latency than specific activity. It is concluded that trailing conscious-experience-generating impulses are elicited by collateral activity from the specific information received from the first stimulus. These impulses reach the cortex at the same moment as the specific activity of the second (masking) stimulus as coded, which has a relatively higher signal-to-noise ratio in the given retinotopically specified cortical space. Consequently, subjects consciously perceive the second stimulus. This operation of awareness generation is termed perceptual retouch and is considered as a special psychological mechanism worthy of psychophysical study.
\end{abstract}

Classical works in the physiology of arousal and nonspecific sensory systems have proved convincingly that the neurophysiological substrate necessary for energizing the brain and providing sufficient activity for the manifestation of conscious experience (perceptual awareness) is located subcortically and consists of the brainstem reticular formation and nonspecific thalamic activating system (Dixon, 1971; Jasper, Proctor, Knighton, Noshay, \& Costello, 1958; Magoun, 1958; Riklan \& Levita, 1969; Smirnov, Muchnik, \& Shandurina, 1978; Worden, Swazey, \& Adelman, 1975).

The importance of energetic, rather than purely structural or algoristic, processes in visual masking and information processing is rarely stressed. It has been shown, however, that percepts evolve and accumulate over time (Eriksen \& Schultz, 1978). This perceptogenetic or microgenetic process takes a relatively long time (see Bachmann, 1977, 1980; Flavell \& Draguns, 1957; Kahneman \& Norman, 1964; Kragh \& Smith, 1970; Lange, 1893; Nikitin, 1905; Vekker, 1974). Furthermore, the time for specific impulses to reach the highest levels of the nervous system is much shorter than the whole microgenetic process. Thus, we have reason to believe that, first, much of this evolution of subjective experience of

The author wishes to convey his sincerest thanks to Professor Charles W. Eriksen for his most generous help in making this article more idiomatic and succinct. The author's mailing address is: Department of Psychology, Tartu State University, 78 Tiigi Street, Tartu, Estonian SSR, 202400 U.S.S.R. the presented actual input consists of heterarchic cyclic activity rather than purely of afference, and, second, the temporally trailing nonspecific sensory activities play a crucial role in this process.

The present article will argue that, in visual masking, the interaction of specific sensory systems with nonspecific "energizing" pathways is crucial.

\section{The Specific and Nonspecific Afferent Systems Interaction and the Postulation of Perceptual Retouch}

By now, it is generally accepted that the afferent impulses necessary for perception can reach the cortex through the two related, but functionally different, systems: first, via the set of modality-specific (and pattern-specific) channels, and second, by the nonspecific arousal system that is located in the brainstem reticular formation and in the site of the generalized thalamic nuclei. As a rule, this nonspecific system is activated by the collaterals from the specific system. To paraphrase Kimble (1977), the specific system provides the contents of consciousness, the what-is-it type of data, whereas the reticulothalamic system provides, in its interaction with cortical neurons, necessary background arousal for consciousness itself. Synaptic input from both the systems converges onto cortical neurons building up an overlapping bifunctional map of afference (see Gellhorn, 1961; Hassler, 1978; Jasper, 1966; Mountcastle, 1966; Smirnov et al., 1978).

The data for substantiating the given explanation include: Dependence of sleep and wakefulness dy- 
namics - that is, unconsciousness and consciousnesson the activity of the nonspecific system; demonstrations of EEG desynchronization similar to the awake pattern when the reticular formation of anesthetized animals is electrically stimulated; detrimental effects of the subcortical critically localized tumors to conscious states (e.g., nonspecific destruction in parallel with intact primary afferents leads to coma); modification of the cortical sensory evoked potentials after stimulation of nonspecific subcortical systems; high correlation between activity in the cortical projections of specific afferent pathways (e.g., the retino-geniculo-striate) and activity of nonspecific afferent neurons in the thalamus; increase in the number of active visual cortical neurons that are responding to the retinal afferents by the stimulation of nonspecific systems; increase in cortical area responding to a given specific afferent when the nonspecific and specific systems interact simultaneously (Bremer, 1935; Homskaya, 1972; Jung, 1958, 1973; Livingstone \& Hubel, 1980; Moruzzi \& Magoun, 1949; Riklan \& Levita, 1969; Singer, 1979; Worden et al., 1975). The crucial role of the subcortex for generation of awareness as such may be deduced from the observations that patients who, because of severe cortical injury, lack any coherent spatiotopic (iconoclastic) knowledge of the sensory input often still possess a certain form of "vague awareness" even though they are unable to see.

For the nonspecific neural activity to yield conscious perceptual awareness, perceptual retouch (PR) is proposed. PR refers to an operation that makes conscious the physiologically present specific stimulus representation. This term is borrowed from the domain of photography and in the present context refers to the process of emphasizing some photographically registered data in order to modify them and/or change selectively their accessibility (e.g., conspicuity) for the observer's perception. ${ }^{1}$ Thus, $P R$ refers to the psychological process which, being only partially under voluntary control of the subject, has functions of (1) alloting the quality of introspective awareness to the formerly preconscious stimulus representation built up by specific neural activities, and (2) locally changing its degree (conspicuity) in perceptual space-time, thus acting as the dynamic levolving and locus-changing) functional focus of perception. PR can be measured by objective experimental methods. The basic measures potentially include latency of retouch, its spatial spread in real time, and estimated conspicuity (contrast, clearness) over spacetime. PR is by no means termed an all-or-none type of process. It can be used for the description of smooth gradients in the introspective clarity of perceptual data. The actual retouch process has both selective and energetic connotations (see Kahneman, 1973, Kragh \& Smith, 1970, and Riklan \& Levita, 1969, for related problems).
Neurophysiological research has divided the nonspecific activation into the two subclasses: phasic and tonic nonspecific activity (Lindsley, 1960; Magoun, 1958; Smirnov et al., 1978). The first variant is chiefly a function of the thalamic nonspecific systems, whereas the second variant presupposes participation of mainly the midbrain reticular formation. Tonic processes are considered crucial for maintaining wakefulness and general arousal background for ongoing activity. Phasic retouch is supposed to be connected with fast actualization changes and orienting in the environment. Later, we shall deal primarily with just the thalamocortical phasic nonspecific retouch. ${ }^{2}$ This is intimately connected with the orienting reflex phenomenon (Sokolov, 1958). When we consider the traditional spatiotemporal stimulus structure in visual masking or other transient paradigms, however, then these situations can be regarded as an input for a miniature orienting reflex together with the evocation of phasic, although relatively time-consuming, nonspecific activity besides the perturbations in conventional primary afference via geniculostriate channels. This points to a consideration of microgenesismicroevolution of the subjective percept over time. ${ }^{3}$

Highly relevant data for the perceptual retouch idea come from the works of Smirnov and his colleagues (Smirnov, 1974; Smirnov et al., 1978) on artificial sensations. They showed that when certain nonspecific thalamic nuclei are excited, via the implantation of electrodes, with specific pathways left unstimulated, then "superoptimal" mental states emerge, including unusual "clarity," "exactness," and "brightness" of the sensory experiences reported by patients. Objective tests performed by such subjects have confirmed these findings. The opposite effects of "blurred," "unclear," or "dull" perception can also be obtained. Often these phantom percepts are clear projections of the perceptual images into outer surroundings. Of special interest is the fact that in certain cases these thalamocortical influences are at first sensed as undifferentiated phosphenes, or white "blobs," with specific spatial localization, which, after stimulus repetition, become figural and categorized (e.g., form square). In terms of the present approach, this can be interpreted as the gradual involvement of a specific representation by the activation of nonspecific afferents; that is, initially "pure" PR later becomes "filled," or assimilated, with data. The two subsystems interact, although they are relatively autonomous anatomically.

In the context of our interest in the transient phasic aspects of PR, the facts about frequency specificity of the thalamocortical interaction are of special importance. It has been shown that, when nonspecific thalamic systems projecting to the cortex are stimulated with relatively low-frequency $(6-12-\mathrm{Hz})$ repetitive impulses, the recruitment response of cortical neurons that follows is similar to the EEG synchron- 
ization pattern characteristic of sleep and inhibition (Dempsey \& Morrison, 1942; Hassler, 1978; Novikova, 1978; Purpura, 1970). However, with high-frequency (13-25-Hz) stimulation, cortical desynchronization follows. The characteristics of subcortical spontaneous firing rate parallel the effects of brain stimulation (Rougeul-Buser, Bouyer, \& Buser, 1978). Later, some implications of the above data for the PR model of masking will be discussed.

It is important to stress that the interaction of specific and nonspecific pathways at the cortical level is not an occasional phenomenon. According to Akimoto and Creutzfeldt (cited in Brooks \& Jung, 1973), two-thirds of the cortical neurons supply convergence of both visual specific and nonspecific impulses. This input mainly provides facilitatory influence. Analogous data about facilitatory subcortical nonspecific influence can be found in Livingstone and Hubel (1980), Scheibel and Scheibel $(1967,1970)$, and Singer (1979). Another important observation with regard to our problem was made by Sasaki (cited in Brooks \& Jung, 1973). It was found that the spatial organization of effective visual cortical receptive fields is temporally unstable, particularly during arousal, but that during sleep or EEG synchronization the stability greatly increases. Because of this regularity and of the fact that the most stable responses of cortical neurons were the early discharges (contrary to the later variability), one can conclude that the spatial instability of the cortical activated foci depends on the spatial instability of cortical retouch projection. Additional support for this possibility comes from the observation that, in contrast to the cortical neurons, receptive fields of the geniculate axons were stable under all test conditions; that is, some synaptic input other than primary visual afferents is responsible for the described variability in the cortical receptive field organization over time.

In sum, then, we see that the PR process has well described neurophysiological foundations with variable spatiotemporal operating characteristics.

\section{PR and the Structure of the Evoked Potentials}

It is important to note that the structure of cortical evoked potentials (EPs), which can usually be classified as responses to transients, can be decomposed so that its specific and nonspecific components can be specified. The first and faster subcomponent of an evoked potential is connected mainly with the specific activity elicited by a sensory stimulus, and the later slower part of the EP reflects, in turn, the nonspecific influence. Only the nonspecific response is associated with fully developed conscious experience by the subject (Dixon, 1971; Hassler, 1978; Homskaya, 1973; Hubbard, 1975; Novikova, 1978; Uttal \& Cook, 1964). In sleep, only the later negative components of an EP are suppressed, unlike the primary specific components, which remain mostly unchanged (Shagass, 1972; Uttal \& Cook, 1964). In general, the negative EP peaks with $80-140$-msec latency are associated with "primary," "spontaneous" sensory activation (Tanis, 1972; Hillyard, Hink, Schwent, \& Picton, 1973; Squires, Hillyard, \& Lindsay, 1973; Puchinskaya, 1974; Schwent, Hillyard, \& Galambos, 1976; Rutman, 1979). In our terms, this negative peak supposedly reflects the operation of PR. In accord with this, it has been shown that there are no differences in EP components with latencies less than $65-80 \mathrm{msec}$ between attentive and inattentive conditions (Picton, Hillyard, Krausz, \& Galambos, 1974; Puchinskaya, 1974).

Thus, we will operationally measure the PR latency and dynamics according to the negative peak around $65-140 \mathrm{msec}$ after stimulation onset. EP components with less than $65-140-\mathrm{msec}$ latency reflect the operation of specific primary afference. Also of interest is the phenomenon of contingent negative variation-the lasting negative deflection of EEG potential just before the presentation of a critical sensory signal-an index of the heightened sensory attention state. We may term this as accumulative PR concentration at the "spatiotopic" locus of an expected signal. In accord with this interpretation of negativity as an index of externally directed attention, Shagass (1972) has demonstrated a considerable decrease in EP negativity during sleep. These conclusions are somewhat tentative, but they seem consistent with many of psychophysical and psychophysiological findings (e.g., Donald \& Little, 1981; Okita, 1981).

\section{Visual Masking in the Light of PR Dynamics}

Many explanations of masking are based on some concrete physiological mechanism. The most popular have been the retinal or cortical lateral inhibition, excitation summation over time, interaction of transient and sustained channels, and the interaction of the activity of distributed cortical representations of stimuli based on the notion of the frequencyspecific channels. It seems that, within this tradition of physiological reductionism, ${ }^{4}$ the physiological mechanism of specific-nonspecific afferent interaction discussed above has been accorded insufficient attention. ${ }^{\mathrm{s}}$

In visual masking experiments, nonmonotonic $U$ shaped masking functions are sometimes found. They are almost paradoxical, since the shorter intervals between the target, or test stimulus (TS), and the distractor (masker, masking stimulus; MS) result in clearer perception of the TS than do certain intermediate or longer intervals. In spite of some other explanations (e.g., the fast inhibitory impulse of the Rashevsky-Landahl neuronal net, Weisstein, 1968; interaction of transient and sustained channels, Breitmeyer \& Ganz, 1976; comparative effects of TS-MS interaction, Bernstein, Smith, \& Adey, 1977; and integration vs. attention switch, Bachmann \& Allik, 1976), it seems possible that the interaction of 
the physiological systems discussed above can explain the time paradox implicit in nonmonotonic backward masking. It can also describe visual masking in general when combined with some other widely accepted factors of this phenomenon. Specifically, it was argued that the temporally trailing phasic nonspecific input to the critical cortical space (the space representing a stimulus with given spatial coordinates) reaches this cortical space at the time when the specific information from the quickly following second stimulus (MS) has its highest signal-to-noise ratio. Hence, the subject is more likely to consciously perceive the MS instead of the TS (Bachmann; 1980).

The microgenetic postulate says that effective perception needs time to mature and that nonspecific PR activity should continuously accumulate on specific input projected from a given receptive field. If the value of the MS onset asynchrony (SOA) falls within this microgenetic temporal quantum, then the still-developing PR process originated by the TS is also "used" by specific signals of the MS. We can model this by comparing the temporal interaction of two stimuli on the basis of hypothetical EPs (Figure 1). In $A$, the principle cortical EP generated by the TS is depicted. The $P_{1}$ component reflects the arrival of TS specific activity, the $N_{1}$ component reflects the arrival of PR activity, and $P_{300}$ reflects the cortical activity paralleling attentive STM analysis and decision making (cf. Rutman, 1979). $B_{1}, B_{2}$, and $B_{3}$ depict analogous EPs of the MSs arriving after the TS within short, intermediate, and long SOAs, respectively. A common time scale is used for all EPs depicted. If we compare $A$ and $B_{1}$ in time, we notice that the $N_{1}$ component of the TS very much overlaps with the $N_{1}$ of the MS. This means that because two PR processes are integrated, two subjective images-those of the TS and the MS-should be integrated, too. In comparing $A$ and $B_{2}$, we observe that the $\mathrm{N}_{1}$ of the TS and the $\mathrm{P}_{1}$ of the MS overlap. According to our view, PR of the TS adds to MSspecific information (the $P_{1}$ component) and sub-

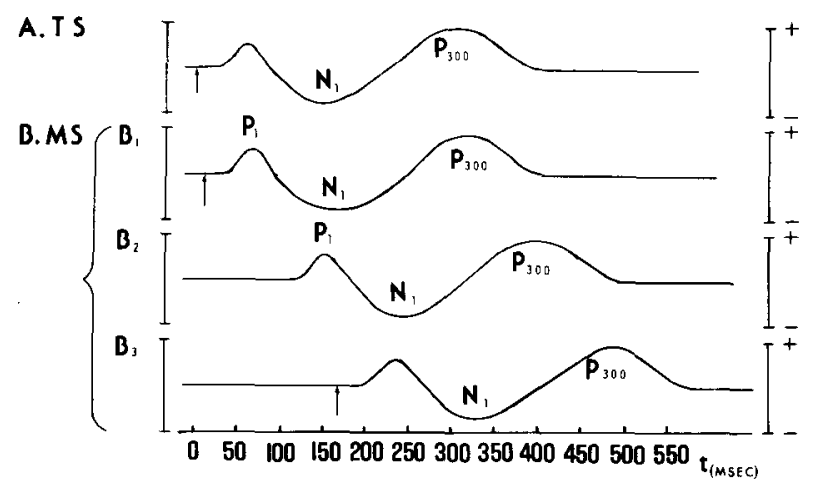

Figure 1. The hypothetical evoked potentials to TS (A) and MS $\left(B_{1}, B_{3}, B_{3}\right)$ with different onset asynchronies between $T S$ and MS equal to 10, 90, and 170 msec. The vertical small arrows indicate the stimulus onset times. jectively the MS information has to have a higher retouch value (clarity, conspicuity, contrast). In comparing $A$ and $B_{3}$, we can see that before the arrival of MS-specific information (modeled by its $P_{1}$ ), the $N_{1}$ of the TS was already built up, which means that a subjectively clear TS percept must precede that of the MS. Thus, the nonmonotonic backward-masking function can be generated, because, at short SOAs, the integration of two retouched stimuli enables readout of the TS into STM; the signal-to-noise ratios of the TS and MS are at a comparable level in the retouched image. (It should be stressed that, in the present EP examples, we do not speak about EPs generated by actual stimulus interaction but simply use them as the models for perceptual dynamics).

We do not often meet such conditions in ecovalid situations because, there, two very short and figuratively different transient stimulations successively paired within a very short interval are very rare. For every single object perceived, specific and nonspecific activities are not dissociated because the exposure times are not suboptimal: The dissociation at the first epoch of microgenesis will be compensated for by the subsequent massive convergence of specific and nonspecific input from the same stimulation. As a rule, $P R$ is more or less invariant during relatively long real-time periods. Maybe the task of searching for a definite page or figure in a book by rapidly thumbing through the leaves can provide an example of the opposite situation. Often in such a situation one may feel as though one were "reading without thought" when one is aware that the perceptual response to the specific pattern being searched for (e.g., a picture or a page number) is lagging behind the motor response of stopping the search. In the example given, the specific information itself is sufficient for the correct response to be made without the subjective experience, which comes later.

Of special import for the explanation of nonmonotonic masking given above are the physiological findings that the difference between the specific and nonspecific latencies is just as large as the most common minima of nonmonotonic masking functions, measured in terms of SOA or, with short stimuli, as an interstimulus interval (ISI). The usual peaks of the U-shaped curves fall within intervals of 30 to $80 \mathrm{msec}$ with the mode around 50 msec (Bachmann \& Allik, 1976; Breitmeyer, 1978; Bridgeman \& Leff, 1979; Fraisse, 1966; Growney, 1978; Growney, Weisstein, \& Cox, 1977; Hellige, Walsh, Lawrence, \& Prasse, 1979; Lyon, Matteson, \& Marx, 1981; Michaels \& Turvey, 1973, 1979; Petry, 1978; Petry, Grigonis, \& Reichart, 1979; Schiller \& Smith, 1966; Turvey, 1973). Magoun's classical work (1958, p. 73) contains relevant data about the comparative times of conduction of the specific and nonspecific sensory impulses. Specific activity reaches the cortex within $11 \mathrm{msec}$, whereas it takes nonspecific impulses on the order of $54 \mathrm{msec}$. Subtracting 11 from 54 equals $43 \mathrm{msec}$, which 
is the interval one would expect to result in maximal backward masking. Hassler's data (1978), as well as the results obtained by Jung (1958), Akimoto and Creutzfeldt (cited in Brooks \& Jung, 1973), and many others, also converge on the same temporal values of specific-nonspecific conduction differences.

A somewhat similar model for the dissociation of primary and secondary cortical responses has been developed by Bridgeman $(1971,1975,1980)$. He stresses the difference between homophotic (akin to the stimulus presentation interval) and metaphotic (after termination of the stimulus) activity in the nervous system. It is shown that, with simulation of metacontrast conditions, early discharges in the cat's visual cortex remain unchanged over the whole range of SOAs used, whereas late activity follows a Ushaped function with minima at SOA $=60 \mathrm{msec}$. Of interest is the finding that the same stimuli which evoke broad late peaks when presented alone, show pronounced minima at nonzero SOAs when presented first. The cells without late peak lead to the minima of late responses with $\mathrm{SOA}=0 \mathrm{msec}$; that 'is, they display monotonic masking. An important aspect of Bridgeman's (1975) findings is that, with masking in some cortical cells being U-shaped, the optic tract and LGN level show only monotonic effects.

Our PR model is very much in accord with much of the Bridgeman (1975) data and his statements that "sensory information is being iteratively recoded in the same network of cells" (p. 97) and that one possibility is that "the first peak (specific signals-T.B.) triggers a system which is ready for input from the cell at the time of the late peak (nonspecific retouchT.B.)" (p. 97). However, his experiments were performed on anesthetized animals, which limits us in comparing the two theories. It is possible, however, that the absence of arousal state creates something like "reversion" or "negative symmetry" of U-shaped activity. The portions of firing inhibition that supposedly create the observed nonmonotonicity in firing rates serve as substitutes for the portions of late activity that would possibly represent the displaced retouch in unanesthetized animals (note that the experiments under discussion used nonbehavioral measures of metacontrast). In other words, the portion of firing suppression between early and late cortical activity would be used instead of the hypothetical $\mathrm{N}_{1}$ component potentially obtainable with alert subjects.

In another electrophysiological metacontrast masking study by Bridgeman (1980), unanesthetized monkeys were used. The enhancement in firing rate for the late poststimulus components (possibly generated by the intrinsic cerebral structures; p. 361) was correlated with correct responding in a metacontrast task contrary to the invariance of the early intervals' activity over correct versus incorrect trials. Although Bridgeman did not discuss the possibility of the participation of a nonspecific system in masking, it seems that his results can be as well interpreted as indicating that performance in masking tasks critically depends on the contribution of the late nonspecific activating impulses to the specific cortical neurons. Because, for some reason, target-related specific neuronal activity receives effective nonspecific PR only on trials when the target is correctly discriminated, Bridgeman's (1980) results are predictable.

Relevant findings for the PR model can be found in the work of Gouras and Padmos (cited in Bridgeman, 1980), who showed that when the stimulus is gradually moved away from the receptive field center, the early component of an occipital eventrelated potential disappears whereas the later components remain almost unchanged; that is, the spatial distribution of late (PR-related-T.B.) activity is wider than that of early activity. Later on, we shall see that one postulated property of the PR process presupposes generation of the "halo" effect surrounding retouched specific information. The relevant experimental facts will also be presented.

Careful observation of the PR dynamics in twotransient masking should make it clear that, according to this description, TS information must remain in the nervous system despite its subjective diminution. Evidence for the presence of sufficiently precise specific sensory information without conscious awareness comes from experiments showing significant impact of masked visual information on performance of various visual tasks (Allport, 1977; Gellatly, 1980; Jacobson, 1974; Kolers, 1957; Kragh \& Smith, 1970; Marcel \& Patterson, 1978; Kapustin, Note 1) and the electrophysiologically proved presence of target-related sensory information during behaviorally effective masking (e.g., Schwartz, Whittier, \& Schweitzer, 1979). In other words, information processing and conscious experience dynamics need not reflect equivalent realities (see also Dixon, 1971; Erdelyi, 1974; Underwood, 1976). Indeed, the very first description of masking which comes into the mind is that masking is occlusion from consciousness or reduction of conscious quality of a particular, specific stimulus-to-be-perceived. To explain masking, one should explain the microstructure of the dynamics of conscious awareness within the psychophysical methodology. The paradigm we choose for this purpose is mutual masking of visual forms.

\section{The Mutual Masking Procedure and the Model}

Classical masking studies have often employed either flashes of light or poorly structured visual noise fields as masks. The pattern masks used also frequently represent fairly ill-defined structures which have no unambiguous meaning. To employ the masking technique in a bit more ecovalid fashion, we can use the mutual masking paradigm (see 
Bachmann \& Allik, 1976; Harcum \& Nice, 1975; Michaels \& Turvey, 1979), in which both inputs to the visual system have equal significance and roughly equal probability to be met in the environment. Another advantage of this situation is that it is now possible to investigate both forward and backward masking at the same time. The same set of trials becomes a source of both functions. The conclusions about differences in backward and forward masking become more powerful. An additional favorable aspect of this technique stems from the fact that, with mutual masking, both stimuli are candidates for processing through the same hierarchy of mechanisms along the whole processing continuum. Both require the same type of response. The only factor that differentiates-with regard to the final set of experimental data-between the TS and the MS is their conventional status depending on the order of presentation.

In an earlier experiment (Bachmann \& Allik, 1976), we presented subjects with two successive geometric forms to the same retinal location using various ISIs, ranging from 0 to $250 \mathrm{msec}$. The stimuli were presented for $10 \mathrm{msec}$ each. The subject's task was to recognize both stimuli. Recognition performance of the first stimulus $\left(\mathrm{S}_{1}\right)$ generates the backward masking function, and that of the second stimulus $\left(S_{2}\right)$, forward masking. Figure 2 represents the principle outcomes of that experiment. As shown, backward masking was nonmonotonic with maximum masking at intermediate SOAs from 30 to $90 \mathrm{msec}$, whereas the forward masking function was monotonically increasing and asymptoted more rapidly. In terms of forward-backward difference and the value of maximum-masking ISI (SOA) in backward masking, these functions are very similar to the wide number of masking curves from several other experiments (e.g., Fraisse, 1966; Hellige et al., 1979; Michaels \& Turvey, 1973, 1979; Turvey, 1973).

An attempt to explain the experimental results shown by the proposed PR model of specific-nonspecific interaction follows. But first an important

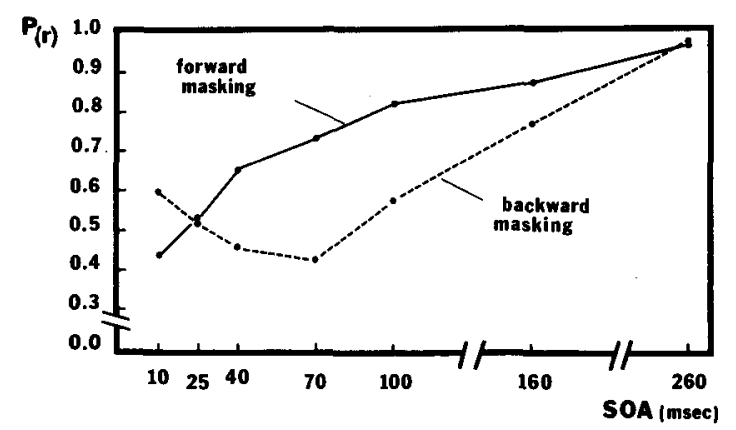

Figure 2. The functions of forward and backward masking obtained by mutual making of visual forms, adapted from Bachmann and Allik (1970). Probability of correct recognition is on the ordinate, and stimulus onset asynchrony is on the abscissa. remark with regard to the time of processing needs to be made. If we compare the usual reaction times in recognition tasks and the critical intervals of masking, it is apparent that these two differ considerably. In an ingenious backward masking study, Krol and Tanenholtz (1976), after subtracting the response generation and execution phases from total reaction time, showed that the minimal SOAs between the TS and MS required to provide TS recognition were several times shorter than the whole recognition time. The EP components associated with final attentive decisions about stimulus (e.g., $\mathbf{P}_{\mathbf{3 0 0}}$ ) also have latencies considerably longer than the critical-threshold SOAs in masking. It follows that the perceptual results of stimulus interaction in masking needed to be analyzed in order to give a perceptual report about the stimuli (see also Eriksen \& Schultz, 1978). In other words, recognition in visual masking can be understood as a short-term memory analysis of the visual results of a TS-MS interaction. But what are these visual results themselves dependent upon SOA? Let us consider the hypothetical interaction of $S_{1}$ and $\mathrm{S}_{\mathbf{2}}$ in mutual masking conditions at different SOAs and keep track of the functions in Figure 2.

Short SOAs (10-25 msec). The specific neural signals which activate the codes of both $S_{1}$ and $S_{2}$ reach the visual cortex before the nonspecific activation evoked by both stimuli arrives at the critical cortical space. With the subsequent arrival of these retouch impulses, the signal-to-noise ratio of both stimuli is at a comparable level and the specific representations of both $S_{1}$ and $S_{2}$ are activated equally effectively. The perceptual outcome will be the conscious retouch of the $S_{1}-S_{2}$ composite and its intake to visual STM, with masking dependent (1) on the relative background luminances of $S_{1}$ and $S_{2}$ (the luminancesummation/contrast-reduction aspect; cf. Eriksen's, Hellige's, and Navon's work), (2) on the relative ease of readout or comprehension of stimuli ("montage""camouflage" explanation; cf. Eriksen et al.), and (3) probably on the relative impact of the stimuli in evoking lateral inhibition in the specific representation systems (e.g., in distributed representations; see Weisstein, Harris, Berbaum, Tangney, \& Williams, 1977) or in less specific inhibitory networks (see Bridgeman \& Leff, 1979). ${ }^{6}$ In other words, at the short SOAs, stimuli undergo simultaneous percept microgenesis and the behavioral outcome depends on the subsequent cognitive processing of this composite visual percept. In the case of very high energies of $M S$ or in the case of MS construction being such that it is impossible to read out the TS from the composite percept, our first phase of the masking curve should be considerably lowered and, thus, backward masking is potentially monotonic. The same applies to "hypertrophic" MS on-times (e.g., Hernandez \& Lefton, 1977; Lefton, 1970), during which the long MS on-period "absorbs" the whole microgenesis 
and inevitably the MS has priority as a material to be retouched. The first phase of the U-shaped function should thus be eliminated; this would result in a monotonic function. Another condition that predicts monotonic masking is that in which the TS is too weak in comparison with the MS. Then the difference in reaction latencies within the nervous system makes the physically intermediate intervals (e.g., $60 \mathrm{msec}$ ) physiologically simultaneous. The TSand MS-specific signals become, in effect, simultaneous only beginning with the intermediate intervals; at shorter SOAs, the weak TS input is overridden by the MS.

In our example (Bachmann \& Allik, 1976), probably due to the equal submedium energies of the $S_{1}-S_{2}$ backgrounds and the imperfect camouflage of the stimuli when superimposed, the shortest SOAs were not totally detrimental for stimulus recognition, thus enabling the U-shaped function.

Intermediate SOAs $(40-90 \mathrm{msec})$. The specific neuronal code of the specific representation of $S_{1}$ is activated at central levels before the nonspecific impulse (in our model, the thalamic phasic activation via collaterals) evoked by it catches the corresponding specific input in that cortical space. During the time of buildup of nonspecific PR for the represented $S_{1}$, its signal-to-noise ratio and neural trace strength diminish while the specific input from $S_{2}$ reaches central representation which has a retinotopically overlapping receptive field with $S_{1}$ representation. At the moment of the arrival of nonspecific activation generated by $S_{1}$ to the neuronal representations, the $S_{\mathbf{2}}$ signal-to-noise ratio is maximal and supposedly higher than that of $S_{1}$. The outcome at the conscious retouch zone is that $S_{2}$ has considerably higher contrast or clarity. The process is somewhat akin to permutations in two-transient integration, with PR being the agent. Also, the given mechanism allows both all or none outcomes of masking as well as the relative TS-MS conspicuity differences. Thus, it can serve as the physiologically based foundation for the relativistic or comparative psychophysical description of masking developed in the important studies by Bernstein (e.g., Bernstein et al., 1977). We feel that the PR model and Bernstein's theory are compatible in that the former gives a description of the microgenetic processing mechanism responsible for certain perceptual outcomes, while the latter describes a psychophysical operation used for the evaluation and analysis of a retouched image in STM.

If the percept in the case of intermediate SOAs is further analyzed by the higher cognitive systems in STM, then the $S_{2}$ certainly has an advantage. In our functions (Bachmann \& Allik, 1976), this is reflected by the significant difference between the $S_{1}$ and $S_{2}$ recognition levels in favor of the latter. This relative sublimination of $S_{1}$ might be termed the dynamics of spontaneous attention.
An important fact is that the critical SOAs leading to the strongest backward masking are similar to the difference between the temporal values that specify, respectively, the specific and nonspecific conduction times for reaching the central parts of the nervous system. And this is the core prediction of the present model-maximum masking at SOAs equal to the value of the temporal lag of PR behind the specific input.

Longer SOAs $(90-250 \mathrm{msec})$. With ever increasing SOA, the PR initiated by $S_{1}$ reaches the $S_{1}$ specific codes before the $S_{2}$ specific content arrives at the cortical level. This leads to a situation in which $S_{1}$ obtains an ever more clear conscious quality before the $S_{2}$ retouch. But with $S_{1}-S_{2}$ intervals of $90-150 \mathrm{msec}$, masking still persists with backward masking stronger than forward masking. Suppose the interval between the two fast retouched inputs equals $90-100 \mathrm{msec}$. Since total processing time is considered to be still longer, we are dealing with a situation in which the $\mathrm{S}_{2}$ is retouched while the cognitive analysis of the retouched subjective visual image of $S_{1}$ is still continuing. This fairly sudden appearance of some new visual object in the subject's consciousness may cause a switching of attention for the cognitive coding of the $S_{2}$ visual image. ${ }^{7}$

An indirect confirmation for an attentional explanation for visual masking comes from the work of Eriksen and his colleagues on visual attention (Colegate, Hoffman, \& Eriksen, 1973; Eriksen \& Collins, 1969; Eriksen \& Hoffman, 1972; Eriksen $\&$ Rohrbaugh, 1970). They have shown that the time needed to switch visual attention is at least 100 $150 \mathrm{msec}$. But this is the time interval we are presently concerned with and the one at which masking functions often asymptote.

Introspective evidence for the possibility of attention switching is provided by showing that (1) subjects often report having seen a clear TS, but that its duration was too short to give a report (Haber \& Standing, 1968; Liss, 1968); (2) the first interval yielding reliable judgments of two successive separate inputs equals about $100 \mathrm{msec}$, and (3) at these intervals, word versus nonword stimuli yield different results (Michaels \& Turvey, 1979).

With SOA approaching the intervals above $200 \mathrm{msec}$ - often found to be the time needed for the whole recognition process-both stimuli are recognized (see Figure 2). Separate integrations of specific and nonspecific activity and separate STM analyses have been successively performed on both $S_{1}$ and $S_{2}$.

In principle, a relatively simple formula can be used for modeling the nonmonotonic backward masking function, which in general behaves analogously to the empirical data from the mutual masking experiments (Bachmann \& Allik, 1976; Michaels \& Turvey, 1979). It is based on the assumption of different conduction times for specific and non- 
specific input to cortical analyzers. The minima of the backward-masking functions are obtained when the difference in the values of specific and nonspecific conduction times $\left(T_{n s}-T_{s}\right)$ combines with the similar SOA value, so that, in relative terms the retouch of $S_{2}$ is maximal and the retouch for $S_{1}$ is minimal. Figure 3 shows a theoretical backward mutual masking function for the case of a hypothetical time constant of $\mathbf{4 0} \mathrm{msec}$ for the difference between specific and nonspecific conduction. For certain critical temporal ranges $(40<\mathrm{SOA}<160 \mathrm{msec}$ ), an additional component for the modification of the theoretical function is added. This reflects the attention switch aspect (tendency to switch to $S_{2}$ encoding beginning with the 40-50-msec SOAs and ending with time values sufficient for successive attentive encoding of two separately retouched inputs at SOAs equal to $150-160 \mathrm{msec}$ ). In Figure 4, both the empirical backward masking functions (from Bachmann \& Allik, 1976, and Michaels \& Turvey, 1979) and the extended theoretical function in which the notions about attention switch are taken into account are depicted.

Suppose we have only five masking theories and three experiments on masking. To compare the relative soundness of the theories, the natural way would be to determine with how many of the experiments each one of the theories appears to be either consistent or inconsistent. For the sake of clarity of argument, let us consider: (1) apparent motion theory (Kahneman, 1967; Logvinenko \& Mirtov, 1980); (2) luminance summation-contrast reduction and integration theory (Eriksen, 1966; Eriksen \& Lappin, 1964); (3) Bernstein's theory (Bernstein et al., 1977); (4) fusion theory (Stoper \& Banffy, 1977), and (5) PR theory.

The first theory postulates that metacontrast, a subclass of masking in which TS-MS contours do not overlap, and apparent motion share the mechanisms of transient stimulus interaction. Violations of the spatiotemporal cues for interstimulus coherence necessary for motion are the main causes of metacontrast suppression.

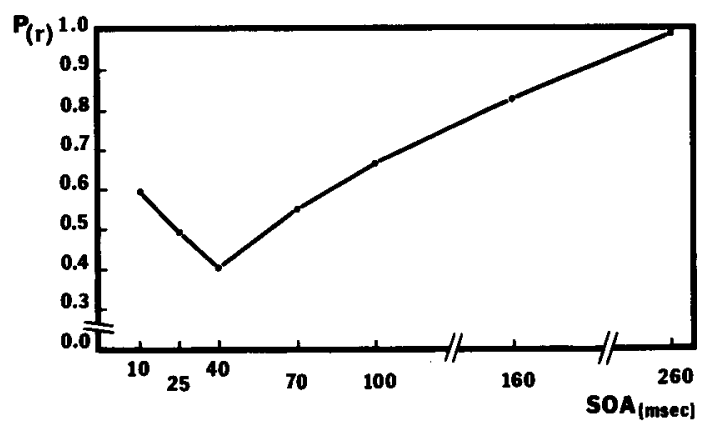

Figure 3. The theoretical backward masking function based on the nonspecific retouch displacement notion with hypothetical specific-nonspecific conduction-time difference equal to $\mathbf{4 0}$ msec.

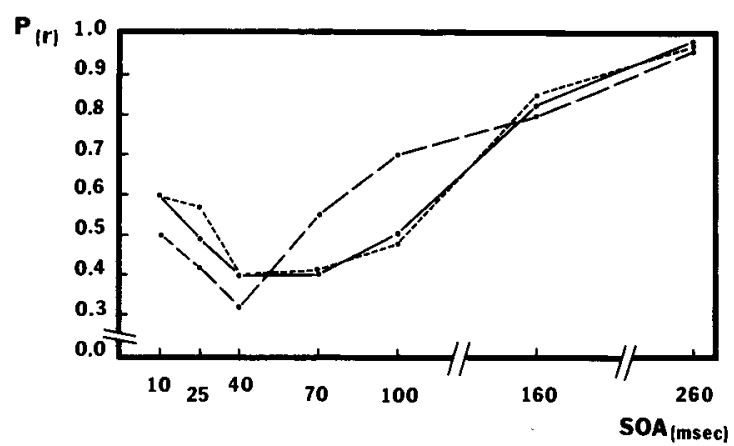

Figure 4. The theoretical backward mutual masking function, based on the integration, retouch displacement, and attention switch mechanisms with hypothetical speclfic-nonspecific conduction-time difference equal to $\mathbf{4 0} \mathrm{msec}$ (solid line), and the empirical backward mutual masking functions adapted from Bachmann and Allik (1976)-short-dashed line-and from Experiment F4, condition T1-T2, by Michaels and Turvey (1979)-long-dashed line.

The integration theory predicts monotonic masking due to the reduced contrast of stimuli presented in close temporal proximity (the mechanism of luminance summation is a special case), which results in the camouflage of TS cues when integrated with MS into a "montage."

In Bernstein's theory, the nonmonotonic metacontrast is assumed to be due to a change in the criterion for reporting TS due to the decaying of the TS trace over time-the longer the SOA, the less the relative conspicuity of TS in comparison with MS. With longer SOAs, TS becomes systematically judged on an absolute basis, rather than on a comparative basis.

The fusion theory explains masking by proposing a fusion process between spatiotemporally close stimuli. The target-relevant excitation is displaced and "absorbed" by the mask-related information.

Suppose further that the three experimental works at hand are those of Schiller and Smith (1966), Carlson and Mayzner (1977) and Didner and Sperling (1980). In the first work it was shown that when the TS-MS pairs with 60 -msec ISI were recycled six times, with the intercycle time equal to $60 \mathrm{msec}$, the formerly suppressed metacontrast stimulus's visibility reappeared. Of the above five theories: the motion theory is inconsistent with this finding; the integration theory can predict this result given some additional statistical assumptions; Bernstein's theory seems compatible due to the reversion of the order of "comparative" and "standard" stimuli; the fusion theory makes no specific prediction; and the PR theory can predict this result on the basis of an assumption of selective PR spatial accumulation after recycling.

In the Carlson and Mayzner (1977) experiment, it was demonstrated that when subjects had to report on MS rather than on TS, the subjective appearance of MS changed, depending on TS shape. It is easy to 
argue that most of the five theories are consistent with this finding-motion theory on the grounds of different movement cues, and integration theory on the basis of the "montage" variance with different targets. Bernstein's theory makes no specific prediction but is not inconsistent. The fusion theory is compatible, and the PR model predicts MS modifications via variance of $P R$ spatial spread with varying $P R$ evoking target stimuli.

Didner and Sperling (1980) showed that when subjects adjusted auditory clicks to coincide with onset of the visual event, the maximum visual perceptual delay (as measured by the largest negative onset interval for a click needed to yield perceived auditoryvisual simultaneity) occurred for TS-MS with 60-90msec SOA. Clearly, the movement theory corresponds to this finding if we suppose that the optimal movement is a visual event that requires the contribution of signals from both stimuli. Then, when symmetrically changing the SOA away from the maximum function value, the first stimulus contribution to the perceived "visual event" increases systemat'ically, independent of the second stimulus. The integration theory is incompatible with the above data because of the nonmonotonicity of the effect. Bernstein's model also seems to be insufficient here because it has no specific prediction for the perceptual delay. The fusion theory, however, may explain the results by an additional proposal stating that the extent of perceptual latency must be proportional to the fusion strength. The PR theory seems to be compatible when we consider that at intermediate SOAs the TS-specific information is most deprived of nonspecific retouch; that is, at these intervals, the MS, being maximally retouched, has the highest probability of becoming a reference stimulus for the "visual event."

All these arguments are summarized in Table 1, where the pluses indicate compatibility of an experimental finding with a given masking theory, the minuses represent incompatibility, and a zero means lack of specific prediction. When we consider a plus as one positive point and a minus as one negative point, then we can calculate the operational validity index (see Table 1.)

Table 1

A Model Table for Calculating the Operational Validity of Different Nonexhaustive Masking Theories

\begin{tabular}{lccccc}
\hline & \multicolumn{5}{c}{ Sample Theories } \\
\cline { 2 - 6 } Experimental Findings & 1 & 2 & 3 & 4 & 5 \\
\hline Schiller \& Smith (1966) & - & + & + & 0 & + \\
Carlson \& Mayzner (1977) & + & + & 0 & + & + \\
Didner \& Sperling (1980) & + & - & - & + & + \\
Operational validity index & 1 & 1 & 0 & 2 & 3 \\
\hline
\end{tabular}

Note $-1=$ movement theory; 2 = integration theory: $3=$

Bernstein's theory; $4=$ fusion theory; $5=P R$ theory.
Table 2 summarizes the different masking theories. The theories chosen are those most common to the current literature, and the material on masking comes from that most frequently found in experimental work on masking. It is clear that both lists are not generated on the basis of an exclusiveness criterion, neither are they exhaustive. Only the most common phenomena and theories are included.

Due to the lack of space, we cannot present the arguments for every single table entry. If some point is explicitly discussed in a certain section of the text, then the respective symbol in the table is marked with the letter "t." Suffice it to say that Table 2 largely depends on our interpretation of the existing theories, most of which are somewhat differently understood among the host of authors, as an analysis of the special literature would easily show.

In Table 2, the plus symbols signify a theory as sufficient to explain a given regularity. The minus sign indicates that a given theory is inconsistent with or contradictory to the given finding. A zero entry means lack of specific prediction of a theory with regard to the given phenomenon. An $\times$ stands for a theory that is consistent when coupled with some other necessary assumption. In calculating operational indexes, each + gives one positive point, each - gives one negative point, and each $\times$ gives 0.5 positive points. For each one of the theories, the summary value of pluses represents an operational sufficiency index for a given theory, the summary value of minuses stands for the operational inconsistency index, and the total sum of plus, minus, and $x$ values, adjusted so as not to yield negative values, provides an operational necessity index. The zero symbol stands for a lack of specific prediction of a given theory as related to a given phenomenon.

As can be seen from Table 2, the PR theory has the highest operational necessity index. We would like to think that this outcome can be interpreted as converging evidence for the possible existence of the phasic $P R$ as the crucial mechanism in producing classical masking phenomena.

\section{Data from Metacontrast Masking Studies in Light of the Proposed Perceptual Retouch Model}

The metacontrast phenomenon is one of the most frequent causes of controversy in masking research. The puzzling aspects include nonmonotonic functions and asymmetry of forward and backward masking in cases when TS and MS are termed arbitrarily and used interchangeably. It seems justified to argue that the power to explain the metacontrast phenomena would be a good test of any masking theory.

To account for the metacontrast effects within PR theory, we propose the following properties of the model: First, the spatial extent of the spread of phasic retouch and its "shaping" in retinotopic terms should be sensitive to the retinotopic arrangement of specific information. This forces us to emphasize that the 
Table 2

The Main Table for Reaching at the Operational Necessity Indexes of Different Masking Theories

\begin{tabular}{|c|c|c|c|c|c|c|c|c|c|c|c|}
\hline \multirow[b]{2}{*}{ Sample Regularities of Two-Transient Masking } & \multicolumn{11}{|c|}{ Sample Theories of Masking } \\
\hline & 1 & 2 & 3 & 4 & 5 & 6 & 7 & 8 & 9 & 10 & 11 \\
\hline \multicolumn{12}{|c|}{ Classical Findings } \\
\hline Monotonic backward masking functions & $\mathbf{X}$ & - & + & $\mathbf{X}$ & $+t$ & + & $\mathbf{X}$ & - & $\mathbf{X}$ & $\mathbf{X}$ & $\mathrm{Xt}$ \\
\hline Nonmonotonic backward masking functions & $\mathbf{X}$ & + & + & + & - & $\mathbf{X}$ & $+\mathrm{t}$ & $+t$ & $+\mathrm{t}$ & $\mathrm{Xt}$ & $+\mathrm{t}$ \\
\hline Asymmetry of forward and backward masking & 0 & + & + & + & - & + & 0 & $\mathbf{X}$ & - & + & $+t$ \\
\hline Symmetry of forward and backward masking & & & & & & & & & & & \\
\hline (e.g., Bernstein et al., 1977) & 0 & - & - & - & + & - & + & + & + & - & - \\
\hline dichoptic presentation & - & + & $\mathbf{X}$ & $\mathbf{X}$ & - & $\mathbf{X}$ & + & + & + & $\mathbf{X}$ & + \\
\hline Masking increase with TS-MS similarity increase & + & $\mathrm{X}$ & $\mathbf{X}$ & 0 & + & - & + & + & + & $\mathrm{X}$ & $\mathbf{X}$ \\
\hline $\begin{array}{l}\text { Decrease in metacontrast masking with increase } \\
\text { in TS-MS spatial separation }\end{array}$ & $+\mathrm{t}$ & $+t$ & $X$ & + & - & $\mathbf{X}$ & + & $\mathbf{X}$ & + & & $+t$ \\
\hline Stronger metacontrast in periphery & + & + & + & 0 & $\mathbf{X}$ & $\begin{array}{l}\hat{0} \\
\mathbf{0}\end{array}$ & o & 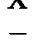 & 0 & $\overrightarrow{\mathrm{X}}$ & $\mathrm{X}$ \\
\hline \multicolumn{12}{|c|}{ Selected Experimental Findings } \\
\hline $\begin{array}{l}\text { Subliminal effects of masked semantic informa- } \\
\text { tion (e.g., Allport, 1977; Marcel \& Patterson, }\end{array}$ & $-t$ & $\mathrm{Xt}_{\mathrm{t}}$ & - & - & $\mathrm{X}$ & - & 0 & $\mathbf{X}$ & + & + & $+t$ \\
\hline Subliminal effects of masked geometric informa- & & & & & & & & & & & \\
\hline $\begin{array}{l}\text { tion (e.g., Kapustin, 1979; Gellatly, 1980) } \\
\text { Masking increase with the increase in TS }\end{array}$ & - & $\mathbf{X}$ & - & - & $\mathbf{X}$ & $-t$ & + & - & $\mathbf{X}$ & $\mathbf{X}$ & $+\mathrm{t}$ \\
\hline $\begin{array}{l}\text { energy (e.g., Purcell et al., 1969, 1975) } \\
\text { The "halo" effect (e.g. Werner, 1935; Stoper \& }\end{array}$ & - & - & - & - & $-t$ & $-t$ & - & $\mathbf{0}$ & $\mathbf{X}$ & - & $+t$ \\
\hline Mansfield, 1978) & $\mathrm{X}$ & 0 & $-t$ & - & $-\mathbf{t}$ & $-\mathrm{t}$ & - & - & $\mathbf{X t}$ & $\mathbf{X}$ & $+\mathrm{t}$ \\
\hline $\begin{array}{l}\text { Reappearance of TS after TS-MS fast recycling } \\
\text { (Schiller \& Smith, 1966) } \\
\text { Lack of spatial frequency specificity of meta- } \\
\text { contrast at the whole SOA range }\end{array}$ & $\mathbf{X}$ & 0 & $\mathbf{X}$ & $\mathbf{X}$ & $+t$ & $\mathbf{X}$ & $+\mathrm{t}$ & $-\mathrm{t}$ & $0 \mathbf{t}$ & 0 & $+t$ \\
\hline $\begin{array}{l}\text { (Growney, 1978) } \\
\text { Nonretinotopic ("spatiotopic") nature of }\end{array}$ & $\mathbf{X}$ & $\mathbf{X}$ & - & 0 & + & + & + & - & 0 & + & + \\
\hline masking (White, 1976; Lehmkuhle \& Fox, 1980) & - & - & 0 & 0 & - & - & 0 & 0 & $\mathbf{X}$ & $\mathbf{X}$ & $\mathbf{X}$ \\
\hline $\begin{array}{l}\text { Asymmetric nonrandom recombinations of } \\
\text { portions of TS and MS into single percept }\end{array}$ & & & & & & & & & & & \\
\hline $\begin{array}{l}\text { (Harcum \& Nice, 1975) } \\
\text { Dependence of MS perceptive quality on } \\
\text { spatial distribution of the backward- }\end{array}$ & - & - & - & - & $\mathbf{X}$ & $\mathbf{X}$ & 0 & - & $\mathbf{X}$ & + & $\mathbf{X}$ \\
\hline masked TS elements (Carlson \& Mayzner, 1977) & $\mathbf{X}$ & - & - & - & $+\mathrm{t}$ & - & $0 t$ & $+\mathrm{t}$ & $+t$ & - & $+t$ \\
\hline Cohene and Bechtoldt effect $(1974,1975)$ & $-\mathrm{t}$ & $-t$ & + & - & $-t$ & + & $\mathbf{X}$ & + & + & $+t$ & $+t$ \\
\hline $\begin{array}{l}\text { The early EP components unchanged with } \\
\text { masking (Bridgeman, 1980) }\end{array}$ & - & + & - & - & + & 0 & $\mathbf{X}$ & 0 & $\mathbf{X}$ & + & $+t$ \\
\hline Operational sufficiency index* & 3.0 & 6.0 & 5.0 & 3.0 & 7.0 & 4.0 & 8.0 & 6.0 & 8.0 & 5.0 & 13.0 \\
\hline Operationa inconsistency index $* *$ & 8.0 & 7.0 & 9.0 & 9.0 & 8.0 & 8.0 & 2.0 & 7.0 & 1.0 & 4.0 & 1.0 \\
\hline Operational necessity index $†$ & 2.5 & 5.5 & 2.5 & 0.0 & 5.5 & 3.0 & 12.0 & 5.0 & 15.0 & 9.5 & 19.0 \\
\hline
\end{tabular}

Note-1 = retinal lateral inhibition; $2=$ central metaphotic lateral inhibition; $3=$ sustained-transient interaction; $4=$ RashevskyLandahl neural net; $5=$ integration theory; $6=$ interruption (erasure) theory; $7=$ Bernstein's theory; $8=$ apparent motion theory; $9=$ fusion theory; $10=$ attention switch theory; $11=P R$ theory. "Sum of + symbols; $a+$ symbol signifies a given theory as sufficient to explain a given regularity. "Sum of - symbols; a - symbol signifies a given theory as inconsistent with or contradictory to a given regularity. TSum of + symbols minus sum of - symbols plus 0.5 times sum of $X$ symbols plus 4.5; 4.5 equals constant needed to add in order to reach at positive values of all necessity indexes. A symbol $t$ indicates that a given table entry is discussed in the text.

term "nonspecific," which refers to certain physiological realities, does not necessarily mean something that is spatially undifferentiated. We can explain the asymmetric nature of traditional metacontrast masking, in which the disk-ring sequence leads to nonmonotonic backward masking but the ring-disk sequence does not, as follows. In the latter case, the nonspecific impulses "find" the smaller disk as well as the form-intact larger areas of the ring dimension, but with the disk-ring sequence, the phasic nonspecific impulses for the smaller central disk "find" an empty hole within a black solid object entirely retouched itself by the following nonspecific impulses of its own. Secondly, the nonspecific retouch system should be tuned especially to forms or patterns as ecologically meaningful wholes. Thus, the gaps and holes within the conventional metacontrast stimuli also become-as a part of an ecovalid stimulusmaterial to be retouched for the subjective experience of the critical object in its entirety.

The spatial resolution capacity for nonspecific activation seems to be not very high. Certainly, it is 
much below conventional spatial resolution in terms of visual acuity. The nonspecific systems lack receptive fields with high spatial resolution. So one could expect the "halo" effect around the form as retouched. This was demonstrated by Werner (1935), in an analysis of the qualitative aspects of metacontrast, and by Purcell, Stewart, and Dember (1968) and Stoper and Mansfield (1978). The findings of the last study strongly point to the possible existence of the nonspecific spatially directed and stimulus-confined phasic retouch process. Two white stimuli were successively presented on a dark background. With intermediate SOAs (50-60 msec), a bright TS and a bright MS formed an introspective composite, in which the area of the larger uniform TS disk was perceptually suppressed just around the smaller MS squares located side by side at the center of the TS (Stoper \& Mansfield, 1978). Subjectively, this appeared as an oblongated "dark hole" in the TS disk containing a pair of bright squares. Thus, the squares seemed to have a surrounding "halo." In other words, the perceptual quality of both the pair of MS forms and their immediate surrounding was retouched. This can be considered as an example of the "shaping" of temporally trailing nonspecific PR activity by the spatial stratification of the stimulus to be retouched.

Due to the temporal lag of nonspecific activity, this suppression of the TS contourless areas, that is, the retouch of the MS in its entirety (i.e., with its ecovalid perceptual spatial context), is highest at the intervals specifying this lag (e.g., $50-60 \mathrm{msec}$ ). In the Stoper and Mansfield (1978) study, the TS contours were relatively far from the MS pair. Thus, they provided the stimulus for an effective PR of their own. These results are difficult to explain on the basis of brightness summation, apparent motion, transientsustained inhibition, or contour formation processes (suppression is contourless!).

The "shaping" assumptions are also supported by the data of Growney et al. (1977), and Weisstein and Growney (1969) which showed that the nonmonotonicity of the metacontrast function increased with a decrease in the spatial distance between TS and MS. The extent of the spatial interaction between TS and MS conflicted with the local inhibitory considerations of metacontrast. In this respect, the concept of lateral inhibition may be viewed from the new perspective as being responsible for the minor effects of metacontrast, whereas consciousness dynamics via PR explain robust metacontrast phenomena. Indeed, why should lateral inhibition as a phenomenon of sensory coding be detrimental to conscious experience, but not to the highly specific unconscious processing of the masked information? (see Gellatly, 1980; Kolers, 1957; Kragh \& Smith, 1970; Marcel \& Patterson, 1978; Murch, 1973.) Instead, we probably observe poor spatial resolution of the nonspecific PR. The problem thus becomes inverse-it is not so much the selective inhibition as it is spatially selective, though not exact nonspecific, facilitation which matters.

In the experiment by Petry et al. (1979), the Ushaped metacontrast masking was considerably reduced when, prior to each trial, subjects had been selectively adapted to flickering MS, with the mean energy level controlled between the flicker adaptation and the control conditions. In addition to the transient channels' fatigue explanation given by Petry et al., one can expect the same result by supposing that, with flickering adaptation, the nonspecific phasic thalamic mechanisms become exhausted, the MS retouch becomes less conspicuous, and the TS receives relatively more attensity on the background of the tonic general activation. ${ }^{9}$ Of the three adapting frequencies used in the Petry et al. study (11.1, 7.7, and $4.8 \mathrm{~Hz}$ ), the $7.7-\mathrm{Hz}$ adaptation decreased metacontrast most. If we consider that the optimal frequencies of stimulation of the thalamic nonspecific system for obtaining cortical EEG synchronization (i.e., deactivation) are 6-8 Hz (Hassler, 1978; Novikova, 1978), this represents a piece of converging evidence for the PR explanation of the Petry et al. (1979) results.

\section{Nonmetacontrast Data Supporting the PR Model}

Good experimental evidence in support of the possibility that displaced facilitation, not inhibition, matters in masking comes from the work of Lawrence (1971). In an elegantly designed experiment, subjects had to name the target item (capital-letter words) embedded in a row of lowercase words presented successively to the same retinal location. With fast presentation rates $(6-19 \mathrm{items} / \mathrm{sec})$, rigorous masking was found. But the results of special interest were that almost $80 \%$ of the errors in fast-presentationrate conditions consisted of reporting the nontarget words and that in roughly $70 \%-90 \%$ of those cases the item reported was the one immediately following the target, with subjects being highly confident in the correctness of their responses. Lawrence (1971) concluded that information in the stimulus which triggers the detection operation is different from the information required for the recognition operation itself. In general, the Lawrence results, which also show low forward masking rates in comparison with backward masking ones, support our hypothesis about the displacement of retouch to the next item.

The results of the Cohene and Bechtoldt (1974, 1975) studies are also well accounted for by nonspecific assumptions. In their studies, subjects had to perform a task of forced-choice recognition of letter pairs on a noise background. The stimuli were formed by the superposition of two quasi-random dotted noise frames. Instead of the presentation of the stimulus halves at different moments in time, as in the original technique used by Eriksen and Collins (1967), 
Cohene and Bechtoldt presented those frames with zero SOA but subtracted one of the halves from the composite after a certain interval. The other half, now a meaningless form, remained intact. (The offset asynchronies were $0 \%-40 \%$ of the bigram duration, which was 50 to $350 \mathrm{msec}$.) Thus, no new physical energy was added to the display, and neither were there new visual features to camouflage the test form. Nevertheless, the masking effect of the "outlasted" part of the composite on bigram recognition was obtained up to total bigram durations of $150 \mathrm{msec}$. It is clear that the results are not easily explained by erasure or lateral inhibition or by most of the specificbased explanations of masking. The needed explanation seems also to be non-sensory. The above authors, as well as some other researchers, point to the possible involvement of attention in visual masking (Bachmann \& Allik, 1976; Di Lollo, Lowe, \& Scott, 1974; Lester, Kitzman, Karmel, \& Crowe, 1979; Michaels \& Turvey, 1979; Pressey, Wilson, \& Harper, 1980). In terms of our model, the Cohene and Bechtoldt effect is explained as being the accumulation of the main portion of PR at the outlasted meaningless part of the stimulus, thus making it the primary material for the following cognitive analysis.

In an electrophysiological study on masking, Lester et al. (1979) obtained additional support for the idea of attention participation in visual masking. It was revealed that, in comparing the trials on which the target was perceived with those on which it was not, the period of largest difference in brain activity was just prior to target onset. Of special interest was an observation that during this period the location of the dipole source in brain activity appeared to shift back and forth between the posterior cortical areas and the midbrain regions. Lester et al. favor the attentionfocusing explanation of masking. It should be added that, first, in this conceptualization, attention should be regarded as a potentially spontaneous stimuluscontrolled phenomenon (like the orienting reflex), though in principle controllable by preliminary adjustments of an observer, and that, second, the nonspecific retouch systems play an important role in this activity. The hit trials were very likely those in which the subjects were successful in building up a sufficiently high preliminary nonspecific activation level prior to TS-MS onset, which then resulted in the perceptual "pop-out" of the TS (cf. also Experiment 2 of Bachmann \& Allik, 1976). In the miss trials, on the other hand, the retouch process might have been more spontaneous and, given the latency assumptions, just MS was considerably more effectively perceived.

Purcell and Stewart (1975) showed that white targets on a dark background were better detected than black targets on a white background and that, paradoxically, the lower energy condition with shorter TS and longer dark ISI between TS and pattern MS yielded better results than the high-energy longer TS condition with constant SOA. An analogous result was obtained for TS luminance increase (Purcell, Stewart, $\&$ Dember, 1969). These results are difficult to explain by luminance summation or interruption hypotheses, but can be accounted for by the nonspecific masking theory. Namely with the white background of TS, one would expect evocation of the more vigorous temporally delayed nonspecific retouch, which consequently makes MS a more favored stimulus. The same logic helps to explain why the shortest, as well as the dimmest, TS can be better detected, viz., the retouch for MS is now the weakest.

\section{General Discussion}

The conscious state is by no means the only basic state of the subjects who are run in experimental laboratories. It is one of the two basic states-the unconscious (1) and conscious (2) states-which have several intermediate gradations in between. If we do not control transitions between those two statesboth local and general transitions-we may expect artifacts. We may term the physiologically welldefined operation that is necessary for the transition from state 1 to state 2 as "retouch," as a special psychological mechanism which is potentially a subject for psychophysical study. This mechanism has two general modes of operation. The first is the tonic mode, which manifests itself in general wakefulness generation/maintenance, in holding the steady level of arousal for attentive conscious state, and in providing nonspecific universal conscious background (i.e., general awareness) for the perceptual activities. The counterconcepts to tonic retouch are the sleep state, unconscious state, etc. On the physiological level, we could consider here the contribution of the midbrain reticular formation. The second, phasic mode of PR manifests itself in orienting activities, in microgenesis of the subjective percept after substantial change in specific input (including appearance of new input), in changing the spatial focus of perceptual processing (the spatial attention problem), in fading of stabilized images, and in alternate resolving of the perceptual multistability states as in binocular rivalry, mutual masking, perception of ambiguous figures, etc. It can be equated to functional focus or focul retouch of the percepts on the background of the generally invariant activity of the first-mode retouch. On the physiological level, we are likely to speak about the thalamic nonspecific systems here.

Due to the low temporal resolving power of PR, in conditions such as mutual masking of visual forms (Bachmann \& Allik, 1976; Michaels \& Turvey, 1979) faster operating stimulus-specific information can be retouched by the slower PR from the spatially overlapping previous transient input. ${ }^{10}$

Let us summarize the main theoretical and metatheoretical characteristics of the proposed PR mask- 
ing theory: (1) Contrary to a great number of masking theories based on notions of stimulus-specific coding and processing mechanisms (e.g., the "channels approach"), the PR theory explains robust aspects of masking as resulting from the dynamics of the nonspecific activation process. (2) In masking, we primarily speak about displaced perceptual actualization by PR instead of total inhibition, interruption, or erasure. (3) The PR theory is sensitive to all-or-none types of perceptual outcome of stimulation (occlusion from consciousness) as well as to more relativistic changes in perceptual clarity or conspicuity (differences and gradients in relative contrast of the stimuli in the retouched and integrated percepts; cf. Smirnov et al., 1978). Hence, it is relevant for different tasks and classes of masking measures such as scaling, detection, and recognition. (4) The PR model predicts differences in forward and backward masking in a rather specific manner. (5) The single PR mechanism predicts both monotonic and nonmonotonic masking, depending on stimulus characteristics. Due to the temporal anisotropy of specific coding and nonspecific activation, in certain conditions the PR process integrates primarily the second stimulus for consciousness. (6) It seems that the "shaped" nonspecific temporally trailing retouch serves different functions, depending on the geometric relationships of TS-MS. If, with overlap, a large portion of MS parts cover the TS geometry, then PR also emphasizes TS within the composite, but with higher MS signal-to-noise ratio than that of TS. " However, with different MS and TS, the PR mainly emphasizes misleading cues. Thus, a single mechanism can explain the results used by both integration and interruption theorists to prove their standpoints and can explain both metacontrast and nonmetacontrast masking. (7) The present theory, by emphasizing "sublimination" or deprivation of service by conscious awareness, rather than interruption, erasure, or inhibition, can easily accommodate the effects of subliminal perception (cf. Dixon, 1971; Erdelyi, 1974).

With the present approach, we may have some premises to start the development of a more or less general explanation of visual masking. Given that we will have the means to predict and quantitatively describe the perceptodynamics in its relatively nonspecific aspect of conscious experience, we will then have a greater chance to more rigorously approach the important issues of specific visual pattern coding in spatiotemporal stimulus interaction.

The most important tasks needed in experimental research to verify and develop the PR theory include: (1) Specification of the conditions enabling differentiation between phasic and tonic subclasses of the retouch process, or in other words, ascertainment of the conditions under which the stimuli in transient paradigms can be detected "at the first place" on the basis of tonic preliminary retouch background without need for phasic and microgenetically accumu- lating PR; (2) specification of the times of the PR process dependent on subjective and stimulus factors; (3) specification of the spatial constraints and dependencies of the spatial stratification of the PR; (4) study of the spatiotemporal regularities of PR focus movement in real time, and (5) generalization of the PR theory to other transient and rivalry paradigms besides masking.

Regardless of the minor revisions and new developments in the physiology of sensory coding and arousal, the classical conception about specificnonspecific afferent systems interaction seems quite valid in general. Due to the central role of the concept of consciousness in psychology and because of its good fit with the spatiotemporal nature of the specific-nonspecific systems interaction, the PR psychophysical model seems justified. Indeed, "models of visual information processing must be developed within the constraints set by the physiological nature of the visual system" (Eriksen \& Schultz, 1978). It is our conviction that this should not necessarily inaugurate the "silly season" (Uttal, 1971).

\section{REFERENCE NOTE}

1. Kapustin, V. L. [On the subliminal generation of visual illusions] (in Russian). Paper presented at the All-Union Meeting of the Young Psychologists, November 1979.

\section{REFERENCES}

AllPort, D. A. On knowing the meaning of words we are unable to report: The effects of visual masking. In S. Dornic (Ed.), Attention and performance (Vol. 6). Hillsdale, N.J: Erlbaum, 1977.

Bachmann, T. [Contemporary psychophysics, phenomenology of experiment, and information processingl (in Russian). Acta et Commentationes Universitatis Tartuensis No. 429. Studies in Psychology 6, 1977, 11-33.

Bachmann, T. Genesis of a subjective image. Acta et Commentationes Universitatis Tartuensts No. 522. Problems of Cognitive Psychology, 1980, 102-126.

BachmanN, T., \& Allik, J. Integration and interruption in the masking of form by form. Perception, 1976, 5, 79-97.

Bernste in, I. H., Smith, D. B., \& Adey, M. Perceptual and response interdependencies in visual masking. In S. Dornic (Ed.), Attention and performance (Vol. 6). Hillsdale, N.J: Erlbaum, 1977.

Bre ITMEyer, B. G. Metacontrast masking as a function of mask energy. Bulletin of the Psychonomic Society, 1978, 12, 50-52.

BRE ITMEYER, B. G., \& GANz, L. Implications of sustained and transient channels for theories of visual pattern masking, saccadic suppression, and information processing. Psychological Review, 1976, 83, 1-36.

Bremer, F. Cerveau isolé et physiologie du sommeil. Compte Rendu de la Société de Biologie (Paris), 1935, 118, 1235-1241.

Bridgeman, B. Metacontrast and lateral inhibition. Psychological Review, 1971, 78, 528-539.

Bridgeman, B. Correlates of metacontrast in single cells of the cat visual system. Vision Research, 1975, 15, 91-99.

Bridgeman, B. Temporal response characteristics of cells in monkey striate cortex measured with metacontrast masking and brightness discrimination. Brain Research, 1980, 196, 347-364.

Bridgeman, B., \& LEFF, S. Interaction of stimulus size and retinal eccentricity in metacontrast masking. Journal of Experi- 
mental Psychology: Human Perception and Performance, 1979, 5, 101-109.

Brooks, B., \& Jung, R. Neuronal physiology and the visual cortex. In R. Jung (Ed.), Handbook of sensory physiology (Vol. VII/3): Central processing of visual information (Part B). New York: Springer-Verlag, 1973.

Carlson, K., \& Mayzner, M. S. A reassessment of target-mask interaction in visual backward masking. Bulletin of the Psychonomic Society, 1977, 9, 227-229.

Cohene, L. S., \& Bechtoldt, H. P. Visual recognition as a function of stimulus offset asynchrony and duration. Perception \& Psychophysics, 1974, 15, 221-226.

Conene, L. S., \& Bechtoldt, H. P. Visual recognition of dotpattern bigrams: An extension and replication. American Journal of Psychology, 1975, 8, 187-199.

Colegate, R. L., Hoffman, J. E., \& Eriksen, C. W. Selective encoding from multielement visual displays. Perception \& Psychophysics, 1973, 14, 217-224.

DempSEY, E. W., \& Morrison, R. S. The production of rhythmically recurrent cortical potentials after localized thalamic stimulation. American Journal of Physiology, 1942, 135, 293-300.

Didner, R., \& Sperling, G. Perceptual delay: A consequence of metacontrast and apparent motion. Journal of Experimental Psychology: Human Perception and Performance, 1980, 2 , 235-243.

Di Lollo, V., Lowe, D. G., \& ScotT, J. P., Jr. Backward masking and interference with the processing of brief visual displays. Journal of Experimental Psychology, 1974, 103, 934-940.

Drxon, N. F. Subliminal perception: The nature of a controversy. London: McGraw-Hill, 1971.

Donald, M. W., \& Litrte, $R$. The analysis of stimulus probability inside and outside the focus of attention, as reflected by the auditory $\mathrm{N}_{1}$ and $\mathrm{P}_{3}$ components. Canadian Journal of Psychology, 1981, 35, 175-187.

Erdelyi, M. H. A new look at the New Look: Perceptual defense and vigilance. Psychological Review, 1974, 81, 1-25.

Eriksen, C. W. Temporal luminance summation effects of backward and forward masking. Perception \& Psychophysics, 1966, 1, 87-92.

Eriksen, C. W., \& Collins, J. F. Some temporal characteristics of visual pattern perception. Journal of Experimental Psychology, 1967, 74, 476-484.

Eriksen, C. W., \& Collins, J. F. Temporal course of selective attention. Journal of Experimental Psychology, 1969, 80, 254-261.

Eriksen, C. W., \& Hofrman, J. E. Temporal and spatial characteristics of selective encoding from visual displays. Perception \& Psychophysics, 1972, 12, $201-204$.

Eriksen, C. W., \& LAPPIN, J. S. Luminance summation-contrast reduction as a basis for certain forward and backward masking effects. Psychonomic Science, 1964, 1, 313-314.

Eriksen, C. W., \& Rohrbaugh, J. W. Some factors determining efficiency of selective attention. American Journal of Psychology, 1970, 83, 330-342.

ERiksen, C. W., \& Schultz, D. W. Temporal factors in visual information processing. In J. Requin (Ed.), Attention and performance (Vol. 7). Hillsdale, N.J: Erlbaum, 1978.

Flavell, J. H., \& Draguns, J. A microgenetic approach to perception and thought. Psychological Bulletin, 1957, 54, 197-247.

Fraisse, P. Visual perceptive simultaneity and masking of letters successively presented. Perception \& Psychophysics, 1966, 1, 285-287.

Gellatly, A. R. H. Perception of an illusory triangle with masked inducing figure. Perception, 1980, 9, 599-602.

Gellhorn, E. Cerebral interactions: Simultaneous activation of specific and unspecific systems. In D. E. Scheer (Ed.), Electrical stimulation of the brain. Austin: University of Texas Press, 1961.

GrownEy, R. Metacontrast as a function of the spatial frequency composition of the target and mask. Vision Research, 1978, 18, 1117-1123.
Growney, R. L., Weisstein, N., \& Cox, S. I. Metacontrast as a function of spatial separation with narrow line targets and masks. Vision Research, 1977, 17, 1205-1210.

Haber, R. N., \& Standing, L. Clarity and recognition of masked and degraded stimuli. Psychonomic Science, 1968, 13, 83-84.

Harcum, E. R., \& Nice, D. S. Serial processing shown by mutual masking of icons. Perceptual \& Motor Skills, 1975, 40, 399-408.

HASSLER, R. Interaction of reticular activating system for vigilance and the truncothalamic and pallidal systems for directing awareness and attention under striatal control. In P. A. Buser \& A. Rougeul-Buser (Eds.), Cerebral correlates of conscious experience. Amsterdam: North-Holland, 1978.

Hellige, J. B., Walsh, D. A., Lawrence, V. W., \& Prasse, M. Figural relationship effects and mechanisms of visual masking. Journal of Experimental Psychology: Human Perception and Performance, 1979, 5, 88-100.

Hernandez, L. L., \& Lefton, L. A. Metacontrast as measured under a signal detection model. Perception, 1977, 6, 695-702.

Hillyard, S. A., Hink, R. F., Schwent, V. L., \& Picton, T. W. Electrical signs of selective attention in the human brain. Science, 1973, 182, 177-180.

HomskayA, E. D. [Brain and activation] (in Russian). Moscow: Moscow University Press, 1973.

HubBard, J. I. The biological basis of mental activity. Reading: Addison-Wesley, 1975.

JACOBson, J. Z. Interaction of similarity to words of visual masks and targets. Journal of Experimental Psychology, 1974, 102, 431-434.

JASPER, H. H. Brain mechanisms and states of consciousness. In J. C. Eccles (Ed.), Brain and conscious experience. New York: Springer, 1966.

Jasper, H. H., Proctor, L. D., Knighton, R. S., Noshay, W. C., \& Costello, R. T. (Eds.), Reticular formation of the brain. Boston: Little, Brown, 1958.

Jung, R. Coordination of specific and nonspecific afferent impulses at single neurons of the visual cortex. In $\mathbf{H}$. $\mathbf{H}$. Jasper et al. (Ed.), Reticular formation of the brain. Boston: Little, Brown, 1958.

Jung, R. (Ed.). Handbook of sensory physiology (Vol. VII/3): Central processing of visual information (Part B). New York: Springer-Verlag, 1973.

Kahneman, D. An onset-onset law for one case of apparent motion and metacontrast. Perception \& Psychophysics, 1967, 2, 557-583.

Kahneman, D. Attention and effort. Englewood Cliffs, N.J: Prentice-Hall, 1973.

Kahneman, D., \& Norman, J. The time-intensity relation in visual perception as a function of the observer's task. Journal of Experimental Psychology, 1964, 68, 215-220.

KImble, D. P. Psychology as a biological science. Santa Monica: Goodyear, 1977.

Kolers, P. A. Subliminal stimulation in problem-solving. American Journal of Psychology, 1957, 70, 437-441.

Kolers, P. A. Some psychological aspects of pattern recognition. In P. A. Kolers \& M. Eden (Eds.), Recognizing patterns: Studies in living and automatic systems. Cambridge: M.I.T. Press, 1968.

Kragh, U., \& Smith, G. J. W. Percept-genetic analysis. Lund: Gleerup, 1970.

Krol, V. M., \& TANenholtz, L. J. [Threshold exposure time and recognition time of object images] (in Russian). In V. D. Glezer (Ed.), Information processing in the visual system. Leningrad: "Nauka," 1976.

LANGE, N. N. [Psychological investigations: The law of perception] (in Russian). Odessa: Tipografiya O.V.O., 1893.

LAWRENCE, D. H. Two studies of visual search for word targets with controlled rates of presentation. Perception \& Psychophysics, 1971, 10, 85-89.

LEFTON, L. A. Metacontrast: Further evidence for monotonic functions. Psychonomic Science, 1970, 21, 85-87. 
LeнмкUнLE, S., \& Fox, R. Effect of depth separation on metacontrast masking. Journal of Experimental Psychology: Human Perception and Performance, 1980, 6, 605-621.

Lester, M. L., Kitzman, M. J., Karmel, B. Z., \& Crowe, G. J. Neurophysiological correlates of central masking. In H. Begleiter (Ed.), Evoked brain potentials and behavior. New York: Plenum, 1979.

LindSLEY, D. B. Attention, consciousness, sleep and wakefulness. In H. W. Magoun (Ed.), Handbook of physiology: Section 1: Neurophysiology (Vol. 3). Washington, D.C: American Physiological Society, 1960.

LISs, P. Does backward masking by visual noise stop stimulus processing? Perception \& Psychophysics, 1968, 4, 328-330.

Livingstone, M. S., \& Huber, D. H. Evoked responses and spontaneous activity of cells in the visual cortex during waking and slow-wave sleep. ARVO 1980. Supplement to Investigative Ophthalmology and Visual Science, April 1980, p. 223. (Summary)

Loovinenko, A. D., \& Mirtov, Yu. N. [Apparent motion and metacontrast: Two sides of the same phenomenon.] Vestnik Moskovskogo Universiteta. Seriya 14: Psikhologiya, 1980, No. 2, 37-47.

Lyon, J. E., Matteson, H. H., \& Marx, M. S. Metacontrast in the fovea. Vision Research, 1981, 21, 297-299.

Magoun, H. W. The waking brain. Springfield: Thomas, 1958.

Marcel, A. J., \& Patterson, K. W. Word recognition and production: Reciprocity in clinical and normal studies. In J. Requin (Ed.), Attention and performance (Vol. 7). Hillsdale, N.J: Erlbaum, 1978.

Michaels, C. F., \& Turvey, M. T. Hemiretinae and nonmonotonic masking functions with overlapping stimuli. Bulletin of the Psychonomic Society, 1973, 2, 163-164.

Michaels, C. F., \& TuRvey, M. T. Central sources of visual masking: Indexing structures supporting seeing at a single, brief glance. Psychological Research, 1979, 41, 1-61.

Monuzzi, G., \& Magoun, H. W. Brain stem reticular formation and activation of the electroencephalogram. Electroencephalography and Clinical Neurophysiology, 1949, 1, 455-473.

Mountcastee, V. B. Final discussion. In J. C. Eccles (Ed.), Brain and conscious experience. New York: Springer, 1966.

Murch, G. M. Visual and auditory perception. New York: BobbsMerrill, 1973.

Navon, D., \& Purcell, D. G. Does integration produce masking or protect from it? Perception, 1981, 10, 71-84.

Nikitin, M. P. [On the problem of formation of visual perceptions. The experimental investigation] (in Russian). Vestnik Psikhologii, Kriminal'noj Antropologii i Gipnotizma, 1905, 2, 112-122.

Novikova, L. A. [Electroencephalography and its use for the analysis of functional states of brain] (in Russian). In A. A. Smirnov et al. (Ed.), The natural-scientific foundations of psychology. Moscow: “Pedagogika," 1978.

Окіта, T. Slow negative shifts of the human event-related potential associated with selective information processing. Biological Psychology, 1981, 12, 63-75.

Petry, S. Perceptual changes during metacontrast. Vision Research, 1978, 18, 1337-1341.

Pethy, S., Grigonis, A., \& Reichart, B. Decrease in metacontrast masking following adaptation to flicker. Perception, 1979, $8,541-547$.

Picton, T. W., Hillyard, S. A., Krausz, H. I., \& Galambos, R. Human auditory evoked potentials: I. Evaluation of components. Electroencephalography and Clinical Neurophysiology, 1974, 36, 179-190.

Pressey, A. W., Wilson, A. E., \& Harper, D. W. Evidence for the role of attentive fields in masking. Perception, 1980, 9, 31-36.

Puchinskaya, L. M. Changes in the averaged evoked potentials to the variable-intensity light stimuli in connection with the perception and attention in man. In M. N. Livanov (Ed.), Basic problems of brain electrophysiology. Moscow: "Nauka", 1974.
Purcell, D. G., Stewart, A. L., \& Dember, W. N. Spatial effectiveness of the mask: Lateral inhibition in visual backward masking. Perception \& Psychophysics, 1968, 4, 344-346.

Purcell, D. G., \& Stewart, A. L. A comparison of white and black targets under conditions of masking by a patterned stimulus. Bulletin of the Psychonomic Society, 1975, 6, 13-15.

Purcell, D. G., Steward, A. L., \& Dember, W. N. Backward masking: Facilitation through increased target-field luminance and duration. Psychonomic Science, 1969, 15, 87-88.

Purpura, D. P. Operations and processes in thalamic and synaptically related neural subsystems. In F. O. Schmitt (Ed.), The neurosciences. Second study program. New York: Rockefeller University Press, 1970.

RikLAN, M., \& Levita, E. Subcortical correlates of human behavior: A psychological study of thalamic and basal ganglia surgery. Baltimore: Williams \& Wilkins, 1969.

Rougeul-Buser, A., Bouyer, J.-J., \& Buser, P. Transitional states of awareness and short-term fluctuations of selective attention: Neurophysiological correlates and hypotheses. In P. A. Buser \& A. Rougeul-Buser (Eds.), Cerebral correlates of conscious experience. Amsterdam: North-Holland, 1978.

Rutman, E. M. [Evoked potentials in psychology and psychophysiology] (in Russian). Moscow: “Nauka,” 1979.

Scheibet, M. E., \& Scheibel, A. B. Anatomical basis of attention mechanisms in vertebrate brains. In G. C. Quarton et al. (Eds.), The neurosciences: $A$ study program. New York: Rockefeller University Press, 1967.

Scheibet, M. E., \& Scheibel, A. B. Elementary processes in selected thalamic and cortical subsystems-the structural substrates. In F. O. Schmitt (Ed.), The neurosciences: Second study program. New York: Rockefeller University Press, 1970.

Schille R, P. H., \& Smith, M. C. Detection in metacontrast. Journal of Experimental Psychology, 1966, 71, 32-39.

Schultz, D. W., \& Eriksen, C. W. Do noise masks terminate target processing? Memory \& Cognition, 1977, 5, 90-96.

Schwartz, M., Whittier, O. M., \& Schweitzer, P. K. Evoked responses to retroactively masked stimuli. Physiological Psychology, 1979, 7, 107-111.

Schwent, V. L., Hillyard, S. A., \& Galambos, R. Selective attention and the auditory vertex potential: I. Effects of stimulus delivery rate. Electroencephalography and Clinical Neurophysiology, 1976, 4, 604-614.

Shagass, C. Evoked brain potentials in psychiatry. New York: Plenum Press, 1972.

SINGE R, W. Central-core control of visual-cortex functions. In F. O. Schmitt (Ed.), The neurosciences: Fourth study program. Cambridge: M.I.T. Press, 1979.

Smirnov, V. M. [Electrical stimulation of the human brain and the functional anatomy of mentalityl (in Russian). In N. P. Bechtereva (Ed.), [Neurophysiological mechanisms of mental activity in man]. Leningrad: “Nauka," 1974.

Smirnov, V. M., Muchnik, L. S., \& Shandurina, A. N. [The structure and functions of the cerebral deep structures] (in Russian). In A. A. Smirnov et al. (Eds.), [The natural-scientific foundations of psychology]. Moscow: "Pedagogika," 1978.

Sokolov, E. N. [Perception and the orienting reflex] (in Russian). Moscow: Moscow University Press, 1958.

Squines, K. C., Hillyard, S. A., \& Lindsay, P. L. Vertex potentials evoked during auditory signal detection: Relation to decision criteria. Perception \& Psychophysics, 1973, 14, 265-272.

Stoper, A. E., \& BANFry, S. Relation of split apparent motion to metacontrast. Journal of Experimental Psychology: Human Perception and Performance, 1977, 3, 258-277.

Stoper, A. E., \& MAnsfield, J. G. Metacontrast and paracontrast suppression of a contourless area. Vision Research, 1978, 18, 1669-1674.

TANIs, D. A signal-detection analysis of auditory evoked potentials in an intensity discrimination task. Unpublished Doctoral dissertation, Washington University, 1972.

TURVEY, M. T. On peripheral and central processes in vision: Inferences from an information-processing analysis of masking with patterned stimuli. Psychological Review, 1973, 80, 1-52. 
UNDEkwood, G. Attention and memory. Oxford: Pergamon Press, 1976.

UTTAL, W. R. The psychobiological silly season, or what happens when neurophysiological data become psychological theories. Journal of General Psychology, 1971, 84, 151-166.

UTTaL, W. R. The psychobiology of mind. Hillsdale, N.J: Erlbaum, 1978.

UTtal, W. R., \& Cook, L. Systematics of the evoked somatosensory cortical potential: A psychophysical-electrophysiological comparison. In R. Katzman (Ed.), Sensory evoked response in man. New York: New York Academy of Sciences, 1964.

VEKKER, L. M. [Mental processes] (Vol. 1) (in Russian). Leningrad: Leningrad University Press, 1974.

Weigstein, N. A Rashevsky-Landahl neural net: Simulation of metacontrast. Psychological Review, 1968, 75, 494-521.

Weisstein, N., \& Growney, R. L. Apparent movement and metacontrast: A note on Kahneman's formulation. Perception \& Psychophysics, 1969, 5, 321-328.

Weisstein, N., Harris, C. S., Berbaum, K., Tananey, J., \& Wilinams, A. Contrast reduction by small localized stimuli: Extensive spatial spread of above-threshold orientation-selective masking. Vision Research, 1977, 17, 341-350.

WE RNE R, H. Studies on contour: I. Qualitative analyses. American Journal of Psychology, 1935, 47, 40-64.

WHITE, C. W. Visual masking during pursuit eye movements. Journal of Experimental Psychology: Human Perception and Performance, 1976, 2, 469-478.

Worden, P. G., Swazey, J. P., \& Adelman, G. (Eds.), The neurosciences: Paths of discovery. Cambridge: M.I.T. Press, 1975.

ZABrodin, YU. M., \& Lebedev, A. N. [Psychophysiology and psychophysics] (in Russian). Moscow: "Nauka," 1977.

Zinchenko, V. P., \& Gordon, V. M. [Methodological problems of the psychological analysis of activity] (in Russian). In Systems Research: A Yearbook-1975. Moscow: "Nauka," 1976.

\section{NOTES}

1. One of the advantages of this photographic metaphor is that here, too, we can differentiate between the potential presence of (photographically) coded information and its explicit use via special developing and elaborating procedures which made this information explicit, or actual from the observer's point of view. Also, it is easy to see the principal applicability of the holographic approach here with retouch acting somewhat in the role of a beam of coherent light.

2. $\mathbf{P R}$ is nonspecific in the sense that it is universal, not dependent, as a process, on the specific form of to-be-retouched codes. But as for its result-the image as retouched-the term "specific" can be applied when regarding certain spatiotemporal localization constraints and spatial gradients of retouch distribution.

3. Because of lack of space, we cannot present arguments for the substantiation of microgenesis. For this purpose, consult the following sources: Bachmann (1977, 1980), Eriksen and Schultz (1978), Lange (1893), Vekker (1974), and Zabrodin and Lebedev (1977).

4. See Uttal (1978) and Zinchenko and Gordon (1976) on the potential pitfalls of the reductionist approaches.

5. Almost all theories of masking (except, perhaps, Eriksen's) are exclusively the domain of the specific nervous system conception. But, given the massive data about the bifunctional (specific plus nonspecific) nature of afferent systems, this tradition seems to be unwarranted by the physiological reality of information processing.

6. Why we should consider both luminance summation and feature integration aspects is exemplified in Hellige et al.'s (1979) ingenious studies, where, at the descending phase of backward masking functions, one can find the crossover of curves for different stimuli. Masking extent with TS-MS with maximal spatial overlap and fewer nonoverlapping features (advantage in the case of luminance summation) was smaller than masking extent with TS-MS with little spatial overlap (advantage in the case of readout from the "montage") within SOAs from 0 to $20 \mathrm{msec}$. The inverse trend held across SOAs from 20 to $48 \mathrm{msec}$. Situations in which integration is rather an advantage than a shortcoming for recognition have recently been described by Navon and Purcell (1981) and Schultz \& Eriksen (1977).

7. This is essentially analogous to the Kolers's (1968) clerkcustomer analogy of visual masking and seems to be a special case of limited capacity of cognitive operations with special datalimited constraint in the shape of rapidly fading perceptual transients. From an ecological point of view, and within this limitation, it would be more desirable for an adaptive organism to switch to the coding of a second stimulus at the expense of interruption-or sublimination-of the cognitive coding of an "older" stimulus, because the new input is relatively less deciphered and it is important to quickly ascertain its potential danger or importance.

8. These assumptions may be related to such factors as statistical properties of a model, time constants within which a model holds, constraints on stimulus configurations, TS-MS types and relationships, etc., given that they do not violate the main proposals of a given theory and that a given phenomenon depends directly on the features of a given theory.

9. This explanation resembles similarities with habituation of the orienting reflex-a phenomenon of specific and nonspecific interaction.

10. I would call this reversed "cuckoo-nest effect."

11. Navon and Purcell (1981) and Schultz and Eriksen (1977) have shown how, due to the overlapping TS-MS geometry, detectability can be enhanced at short SOAs.

(Manuscript received April 21, 1981; revision accepted for publication June 28,1983 .) 